\title{
Amazônia: como aproveitar os benefícios da destruição?
}

ALFREDO KINGO OYAMA HOMMA

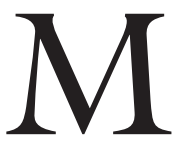

UITO SE TEM ESCRITO sobre a magnitude da região amazônica, sobre seus problemas, sobre as soluções encontradas para eles e sobre suas potencialidades (Alvim, 1972; Becker, 2004; Homma, 2003; Meirelles Filho, 1986 e 2004). A inclusão social, o desenvolvimento adequado e a redução da destruição crônica dos recursos naturais da região vai depender de ações óbvias, tais como maiores investimentos em ciência e tecnologia, em assistência técnica, em infra-estrutura social e vencer o atraso que, aos poucos, torna-se irreversível. Como uma contribuição a esse debate, discutem-se a seguir alguns pressupostos básicos e as possíveis alternativas que precisam ser encarados com determinação por uma política pública de médio e longo prazos.

\section{Inexistência de desenvolvimento sustentável (Daly, 1991)}

A impossibilidade de se viajar mais rápido que a velocidade da luz, de criar ou destruir a matéria-energia ou de criar uma máquina moto-perpétuo como queriam os renascentistas, assim como a existência de um limite para a população de árvores que a terra pode suportar e limite para as populações humanas e de automóveis, mostra que é chegado o momento de se mudar o discurso do "desenvolvimento sustentável" para a Amazônia. Esta só será possível com "desenvolvimento sem crescimento", a despeito das melhorias qualitativas. Muitas propostas ditas sustentáveis em nível local são dependentes de importações de energia ou de outros recursos naturais, baseados em sistemas fechados, com sustentabilidade exógena, em vez de vir endogenamente. A não ser a civilização indígena que viveu na época pré-colombiana, todos os sistemas são insustentáveis, no contexto global. Dessa forma, a preservação absoluta é necessária para determinados ecossistemas, devendo se utilizar integralmente as áreas já desmatadas. Há três discursos conflitantes sobre a sustentabilidade na Amazônia: a do meio acadêmico, a dos organismos de desenvolvimento regional (federal, estadual, municipal ou internacional) e a da sociedade civil que articula a questão social à ecológica, de forma heterogênea (Kinoshita, 1999).

\section{Redução dos desmatamentos e queimadas}

Toda política pública para a Amazônia deve estar voltada para a utilização de mais de 67 milhões de hectares (2004) que já foram desmatados e que constituem a "segunda natureza". Essa área é três vezes a do estado do Paraná ou mais do que a soma dos estados do Rio Grande do Sul, Santa Catarina e Paraná, o que 
mostra o potencial agrícola que poderia ser obtido com a aplicação correta de práticas agrícolas e de atividades mais adequadas. A floresta original é a primeira natureza. Essa utilização fica neutralizada se for mantida a contínua formação de berçários de áreas desmatadas. Há uma diferença entre uma segunda natureza com belas paisagens e uma com restos calcinados da floresta ou de juquira na Amazônia. Metade da Holanda é constituída por áreas que foram conquistadas do mar do Norte; os campos agrícolas do Sul e Sudeste do Brasil; a Floresta Nacional da Tijuca, entre outros, são exemplos da terceira natureza. A Medida Provisória 2.166/2001, que mudou o percentual de área a ser mantida com cobertura florestal para $80 \%$, torna-se inócua, uma vez que a conseqüência dessa medida foi os proprietários adquirirem novas áreas, mesmo em locais distantes, para justificar a utilização das áreas desmatadas, como está ocorrendo com o cultivo da soja. Com isso aumenta o custo efetivo da terra, induzindo o produtor a cuidar da terra a ser trabalhada e da área a ser preservada, a qual, no decorrer do tempo pode ser transformada em nova frente de expansão. Dessa forma, as áreas já desmatadas, ressalvadas as que não deveriam ter sido desmatadas, deveriam ser utilizadas integralmente.

\section{Redução absoluta e relativa da população rural}

Apesar do estereótipo de "povos da floresta", a Amazônia é praticamente urbana. O processo de urbanização da sociedade brasileira não tem sido diferente para a região Norte, onde $70 \%$ da população já é urbana. Atinge $90 \%$ no Amapá, 79\% em Mato Grosso, 76\% em Roraima, 75\% no Amazonas, 74\% em Tocantins, 67\% no Pará e Acre e 64\% em Rondônia. Esses migrantes, ao se dirigirem aos centros urbanos, engrossam os níveis de desemprego e subemprego, favelamento e criminalidade, neutralizam as políticas sociais e as soluções desses problemas envolvem altíssimos custos sociais. Não se pode esquecer que o Nordeste concentra mais de $46 \%$ da população rural do País, representando sempre uma bomba populacional, que, dependendo das circunstâncias, pode migrar em direção à Amazônia (Alves et al., 1999). Se se considerar a mesma população rural do Sudeste para o Nordeste, verifica-se a existência de um potencial migratório superior a oito milhões de habitantes, a qual pode se deslocar para a Amazônia na busca de novas esperanças. Naturalmente que estes impactos não seriam comparados como aos da China, em que $70 \%$ da população é rural e $64 \%$ da população economicamente ativa é do campo.

\section{Desenvolvimento excludente: limpos e sujos}

A inclusão social não pode ser efetuada com a defesa de algumas atividades e a exclusão de outras, necessárias à sociedade. Esse argumento teria validade para a extração madeireira predatória, o garimpo, o desmatamento para pastagens ou para roças, o tráfico de animais, os tóxicos, o carvoejamento com florestas nativas, a prostituição e outras atividades ao redor do mundo como o fumo, os armamentos etc. No caso da Amazônia, é muito comum aconselhar o turismo 
ecológico, as reservas extrativistas, plantas medicinais etc. e condenar a pecuária, a soja, o arroz, o milho, o dendê etc. A sociedade necessita da produção de óleo de soja, da carne bovina, do leite e alguém sempre vai ter que produzi-los, da mesma forma que também precisa de lixeiros, de coveiros, de funerárias etc.

\section{Política de governo e política pública}

É importante não confundir política de governo com política pública. Enquanto a primeira tem duração efêmera e de cunho personalista, a política pública deve transcender os interesses da sociedade. Em 1995, o teórico do emprego William Bridges já anunciava que não "havia mais espaço para todas as pessoas no mercado de trabalho". Para ele, o trabalho autônomo já estaria substituindo o emprego. Tais mudanças seriam semelhantes à que ocorreu na Inglaterra durante a Revolução Industrial, no século XIX. Não se deve, entretanto, defender uma política neoludita, que prevaleceu na Inglaterra nos séculos XVII e XIX, sobretudo em 1811 e 1813 , de destruir as máquinas, consideradas então responsáveis pelo desemprego. Essas transformações ensejam o desenvolvimento da agricultura capaz de absorver grandes contingentes populacionais, gerando renda e emprego, voltada para o autoconsumo familiar, reduzindo ao mínimo as compras externas, bem como, no sentido macrorregional, de procurar equilibrar a balança comercial provocada pelas importações da Zona Franca de Manaus.

\section{Quinta revolução tecnológica}

Nos últimos cinqüenta anos, o País assistiu a quatro grandes revoluções tecnológicas desenvolvidas pelos pesquisadores nacionais (Becker, 2004). A criação da Petrobras, em 1953, levou ao domínio da tecnologia de exploração de petróleo em mares profundos, de modo que se caminha para a auto-suficiência. A criação da Embraer, em 1969, levou o País a desenvolver aeronaves visando a atender mercados regionais, com procura internacional. A criação do Proálcool, em 1975, mostrou a capacidade brasileira de desenvolvimento de motores a álcool e a produção de um combustível alternativo não poluente em grande escala. A fundação da Embrapa, em 1973, que, em conexão com Universidades e Institutos de Pesquisa localizados no Sul, Sudeste e Centro-Oeste, levou ao domínio de técnicas agrícolas que possibilitaram a conquista dos cerrados, transformando-os no maior celeiro de grãos do País. Há necessidade de uma quinta revolução tecnológica que dê conta da Amazônia, visando ao domínio da sua biodiversidade e à descoberta de atividades apropriadas e de novas alternativas econômicas.

\section{Novas atividades: tenham mercado e sejam lucrativas}

Na panóplia da discussão sobre os destinos da Amazônia, duas propostas se destacam na defesa da redução dos desmatamentos e queimadas na região. Uma defende a utilização sustentável da floresta mediante a criação de reservas extrativistas, reservas de desenvolvimento sustentável, manejos florestais comunitários, reservas marinhas e outras acepções nesse sentido. Essa proposta constitui a bandeira de luta dos movimentos ambientalistas, alguns governos estaduais, 
governos de países desenvolvidos, instituições internacionais, o Ministério do Meio Ambiente, o Ibama, o Partido dos Trabalhadores, o Partido Verde, o MST, entre outros. O líder sindical Chico Mendes se constitui como ícone desse modelo de desenvolvimento considerado sustentável.

Essa proposta, defendida sobretudo por parte dos movimentos ambientalistas, nega completamente a atividade pecuária, a extração madeireira, os grandes projetos, a expansão dos grãos etc. O corolário é que mesmo pequenos produtores têm interesse na criação de gado, como mecanismo de poupança da destruição dos recursos naturais e de capitalização. $\mathrm{O}$ fornecimento de leite para atender os grandes laticínios do Sudeste paraense e de Rondônia, por exemplo, é realizado por pequenos produtores, que têm vacas produzindo menos de três litros de leite por dia. A expansão pecuária na Amazônia é decorrente da pressão da demanda por carne e leite, constituindo-se como uma atividade econômica independente de incentivos fiscais. O rebanho bovino regional, com mais de 63 milhões de cabeças, apresenta uma ativa taxa de crescimento vegetativo, não só do País, mas também em termos mundiais. Os processos produtivos agrícolas, pecuários e florestais na Amazônia, com exceção de determinadas atividades, caracterizam-se pela baixa produtividade da terra e da mão-de-obra.

$\mathrm{Na}$ vertente oposta situa-se a defesa da utilização das áreas já desmatadas da Amazônia como a maneira de se reduzir o desmatamento e propostas ambientais como mecanismo de troca. Entre os defensores dessa vertente situam-se aqueles interessados na perpetuação do modelo, quais sejam, as classes produtoras, os empresários e os setores ligados ao agronegócio, os políticos defensores do desenvolvimento para gerar renda e emprego, a maioria dos governos estaduais, entre outros. Em certo sentido, a proposta "desenvolver sem devastar" vem sendo desmoralizada pelo conflito entre a realidade e a prática.

No contexto ambiental, as críticas dos desenvolvimentistas, dos militares (narcotráfico, guerrilha colombiana, soberania etc.) e dos governadores dos Estados da Amazônia legal, com exceção do Acre, tem sido a de bloquear o progresso (restrições contra a construção de hidrelétricas, hidrovias, asfaltamento etc.) e da planetarização da região.

Essas duas propostas apresentam, no entanto, grandes limitações. A primeira pela impossibilidade econômica e social de se atender a um grande contingente populacional. O modelo do Acre não pode ser transplantando para todos os estados da Amazônia Legal que apresentam padrões de desenvolvimento econômico, social, político e histórico diferenciados. A economia extrativa caracteriza-se pela baixa produtividade da terra e da mão-de-obra, limite da capacidade de oferta, aparecimento de substitutos sintéticos, competição com plantios domesticados, válido enquanto o mercado for restrito ou existir recursos extrativos em grandes estoques, como açaí ou madeira etc. O aumento do custo de oportunidade da mão-de-obra pode engendrar outras alternativas econômicas, quando estas passam a ser disponíveis. O argumento da criação de mercados verdes, 
com preços mais valorizados, pode apresentar dificuldades de sustentação com a democratização desses produtos. A antítese poderia levar a um limite de destruição que tornaria irreversível a sua recuperação.

A partir, portanto, dos pressupostos mencionados, listamos algumas ações que precisam contrapor as atuações localizadas de fundo globalizante, à magnitude da Amazônia.

\section{Uso das áreas já desmatadas com atividades e técnicas apropriadas}

A disponibilidade de grandes extensões de terra que podem ser incorporadas ao processo produtivo, como uma parte dos 67 milhões de hectares desmatados na Amazônia até 2004, superior aos 57 milhões cultivados no País, promoveria a conservação por meio do seu uso. Acrescenta-se ainda as áreas "em estoque" dos proprietários de terra, estimadas em cem milhões de hectares e a possibilidade da construção do solo, como a tecnologia que incorporou vastas extensões dos cerrados brasileiros, colocando a agricultura brasileira em posição ímpar no cenário mundial.

A agricultura amazônica apresenta uma grande heterogeneidade tecnológica, com produtores utilizando transplante de embriões, mecanização e alta produtividade, e outros dedicando-se a agricultura de derruba e queima. Há necessidade de se aumentar a produtividade, tanto da terra como da mão-de-obra, de modo a reduzir a utilização dos recursos naturais com a contínua incorporação de novas áreas derrubadas e queimadas. Um dos caminhos para a agricultura familiar seria a "agricultura de jardinagem", com alta tecnologia, em pequenas áreas, obtendo-se a mesma produção de lotes de cinqüenta ou cem hectares com contínua derrubada da floresta densa. O problema não está nas plantas ou animais, mas nos sistemas adotados pelos produtores e na falta de tecnologia apropriada. Se o desmatamento for inevitável por razões de obras infra-estruturais, estas deverão ser efetuadas mediante compensação ecológica.

As oportunidades que se apresentam para a lavoura de biomassa, em substituição à gasolina e ao óleo diesel, colocam a agricultura nacional como privilegiada no desenvolvimento dessas culturas potenciais. As oportunidades para a Amazônia na ocupação de áreas desmatadas apropriadas para o dendê podem colocar o Brasil, a médio e a longo prazos, por meio de um plantio ordenado, próximo da Malásia ou da Indonésia. No contexto da agricultura cabe destaque também para o reflorestamento com vista à produção de cavacos para geração de energia na Europa. O Sudeste asiático conseguiu implantar uma forte agricultura com cultivos tropicais, como seringueira e cacau (levados da Amazônia), dendê, coco, café, caju e mandioca (do restante do País), pimenta-do-reino, cinchona (no passado), entre outros, com tecnologia e propostas concretas de desenvolvimento. Países como a Índia, a China e o Vietnã, conseguiram aumentar a produção de borracha vegetal num curto período, enquanto o Brasil não consegue sair de menos de cem mil toneladas há várias décadas (Figura 1). 


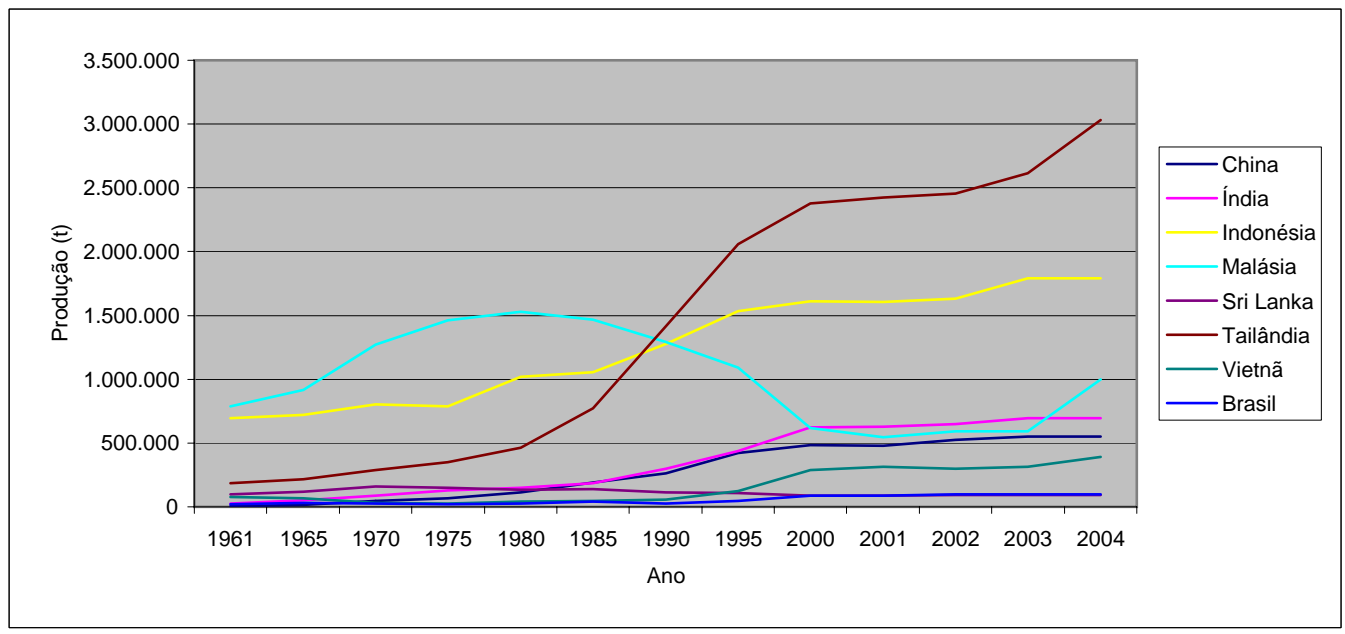

Figura 1 - Produção brasileira e dos principais produtores de borracha natural.

A produção nacional de óleo de dendê abastece apenas do um terço do consumo aparente, indicando a necessidade de se triplicar a atual área em produção estimada em sessenta mil hectares. Se se considerar a opção como biodiesel com 2\% de mistura, seria necessário dispor de mais cem mil hectares (Figura 2). A produção brasileira de óleo de dendê é inferior à de países vizinhos, como Colômbia e Equador.

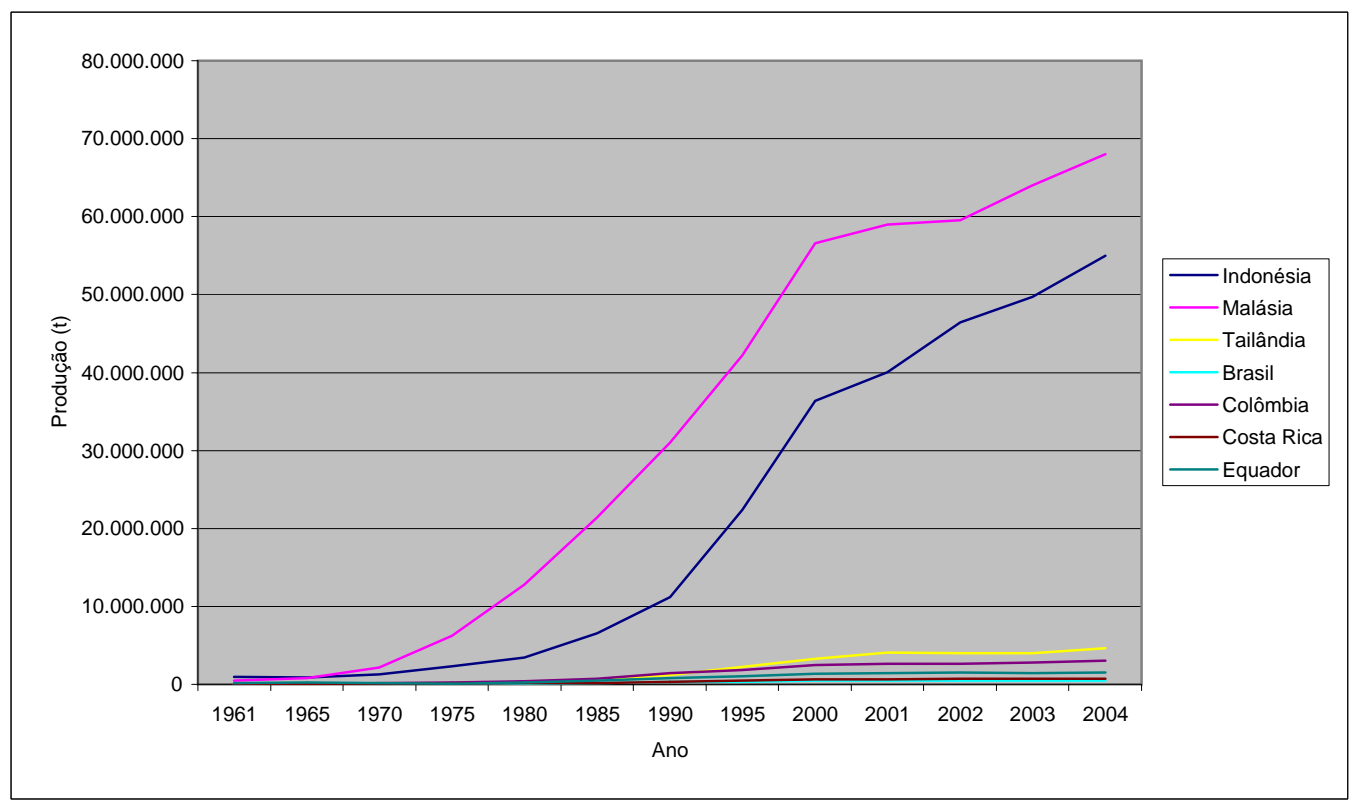

Figura 2 - Posição relativa do Brasil entre os principais países produtores de fruto de dendê.

As importações de borracha natural, em 2003, representaram 64\% do consumo e uma evasão de divisas de mais de US\$ 156 milhões, que vem ocorrendo, 
desde 1951, de forma crescente, mostrando que já deveria ter sido plantada há uma década mais de 170 mil hectares de seringueira. As importações de amêndoa de cacau, em 2003, somam mais de US\$ 116 milhões e quantia equivalente a mais de um terço da produção nacional, reduzida a menos da metade do auge de produção, com a entrada da vassoura-da-bruxa nos cacauais da Bahia, em 1989 (Figura 3).

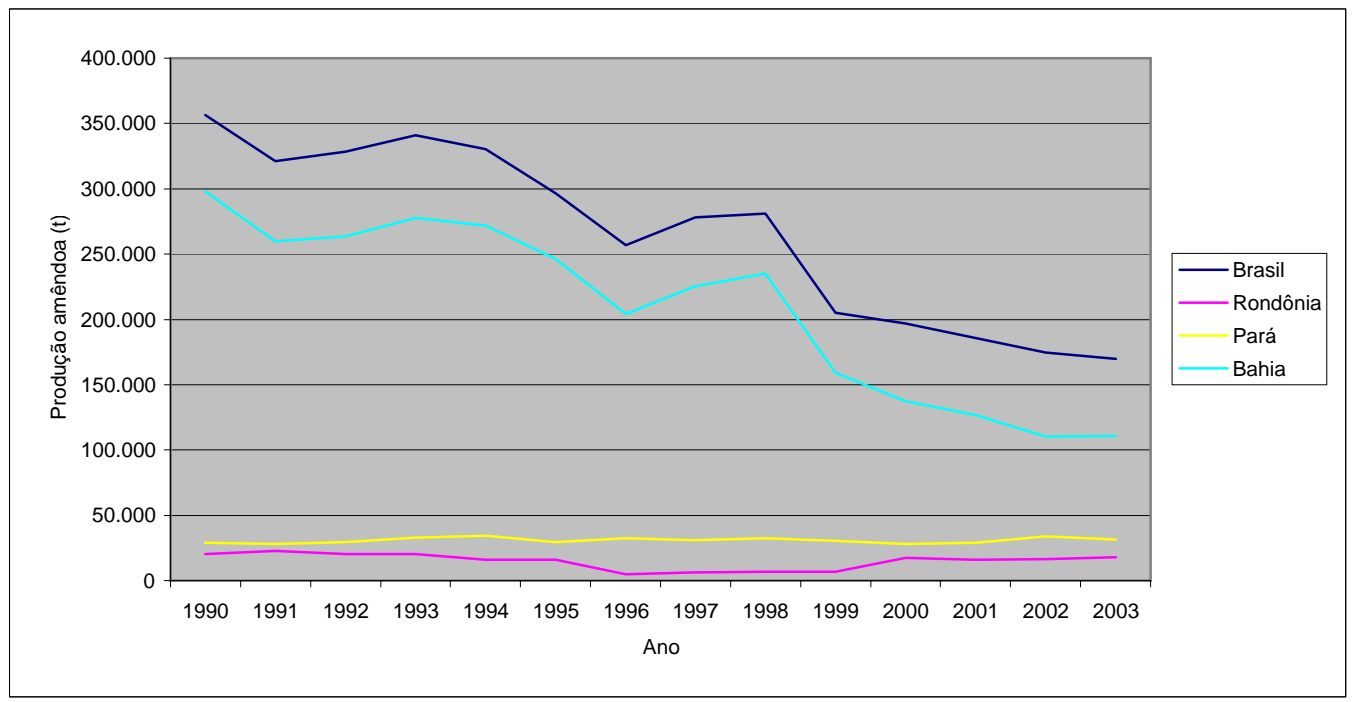

Figura 3 - Produção de cacau em amêndoa do Brasil, Bahia, Pará e Rondônia (t).

Quanto às possibilidades de reflorestamento para a produção de madeiras nobres, compensados, carvão vegetal, celulose, energia e cavacos, estas são as mais amplas possíveis na Amazônia. Para isso, seriam incorporadas as áreas já desmatadas, tanto aquelas com espécies nativas quanto as com espécies exóticas, de modo a reflorestar áreas que não deveriam ter sido desmatadas ou aquelas impróprias para atividades agrícolas, gerando renda e emprego.

O uso das áreas já desmatadas torna-se inócuo se não se conseguir anular a formação dessas novas áreas. Se não for criado um eficiente sistema de fiscalização contra a derrubada de novas áreas que seja apoiado por políticas de incentivo a essa utilização (fertilizantes, calcário e máquinas agrícolas), eles serão meras peças de retórica, como tem sido até o momento.

É provável que com as restrições mais sérias aos desmatamentos e às queimadas, mediante fiscalização, tornando artificialmente escassa a terra em um mundo de abundância, sejam criados mecanismos que levem, com o tempo, à intensificação das propriedades existentes. Esta intensificação, inclusive, já pode ser verificada, especialmente entre os produtores de feijão caupi, culturas industriais como dendê, coco, pimenta-do-reino, maracujá, arroz, milho, soja, algodão, pastagens, cupuaçu, açaí em terra firme, hortaliças etc. Para algumas atividades esta situação está ocorrendo com a expulsão dos ocupantes da agricultura tradicional, que acabam realizando novos desmatamentos em outros lugares. 
Outro aspecto a ser levado em consideração é que não existe consenso entre o que plantar nessas áreas já desmatadas, mesmo por aqueles que defendem a utilização sustentável da floresta.

Para se atingir o desmatamento zero há necessidade, portanto, de políticas concretas, além da restrição da incorporação de novas fronteiras e do financiamento da utilização das áreas já desmatadas. Enquanto o custo de derrubada de novas áreas custa aproximadamente R \$ 200,00 a R \$300,00/ hectare, a utilização das áreas já desmatadas que foram transformadas em "juquira" exige a aradagem, a gradagem, a correção de solos e a reposição dos nutrientes, o que faz com que os custos atinjam R $\$ 700,00$ a R $\$ 750,00 /$ hectare. A diferença de $\mathrm{R} \$ 500,00 /$ hectare indicaria que seriam necessários investimentos da ordem de R $\$ 500 \mathrm{mi}$ lhões para reduzir desmatamentos e queimadas de um milhão de hectares anuais na Amazônia.

\section{Recuperar áreas que não deveriam ter sido desmatadas}

Recuperar áreas que não deveriam ter sido desmatadas deve constituir-se como uma importante alternativa política para a Amazônia. Margens de rios, morros acidentados e pedregosos, áreas importantes para a flora e a fauna, sítios arqueológicos, entre outros, foram implacavelmente destruídos, sobretudo nas últimas quatro décadas. Rios como o Solimões, o Amazonas, o Tocantins, o Araguaia, o Guamá e centenas de outros tiveram suas margens totalmente desmatadas, em menor ou maior grau. Muitos igarapés da mesorregião Nordeste paraense, que foram desmatados há três séculos, ficam completamente secos durante o verão.

Como a maior parte dos afluentes da bacia amazônica tem as suas nascentes nos países vizinhos, que também não escapam ao descontrole dos desmatamentos e queimadas, os riscos assumem dimensão continental, agravada pela pobreza dos países vizinhos (Kinoshita, 1999). Na Colômbia ocorre desmatamento sistemático ao longo do rio Putumayo (no Brasil denomina-se rio Içá) e do rio Caquetá (rio Japurá), e devido à exploração de petróleo na Amazônia equatoriana, peruana e brasileira. Outra parte dos rios tem as suas nascentes no ecótono cerrado/ floresta densa, em cujas cabeceiras verifica-se a expansão da cultura de grãos e da pecuária. Há duas maneiras de se proceder a esta recuperação: uma é deixar a própria natureza regenerar-se com o tempo, protegendo-a da entrada do fogo e de derrubadas futuras. A outra, mediante o reflorestamento, com plantas nativas ou exóticas, em que também será necessário proteger da entrada do fogo, transformando-o em atividade econômica, mediante estímulos e compensações. O sentimento de mea culpa também está induzindo o reflorestamento por muitos àqueles que foram protagonistas da destruição no passado.

Uma grande oportunidade para gerar renda e emprego seria levar em conta a recuperação de áreas desmatadas no Mecanismo de Desenvolvimento Limpo, considerando como crédito de carbono, em vez do enxadrezamento da floresta amazônica por multinacionais. Apesar de tolher liberdades individuais, por exemplo, o financiamento de meio salário mínimo por família durante um tem- 
po mínimo de três a quatro anos para se engajar em programas de reflorestamento de áreas que não deveriam ter sido desmatadas poderia gerar empregos comunitários responsáveis e aumentar a produção agrícola em bases mais apropriadas.

O mercado de crédito de carbono decorrente do aquecimento global leva à criação de novas possibilidades de mercado para atender países desenvolvidos que não conseguiram reduzir seus níveis de emissões ou pretendem manter face aos custos dessa redução $\left(\right.$ Becker $\left.^{1}, 1999\right)$. Os riscos decorrem do fato de os procedimentos não estarem bem definidos, pois se desconhecem os preços da tonelada de $\mathrm{CO}^{2}$ seqüestrado, se haverá envolvimento de desmatamento evitado mediante o bloqueio de áreas de floresta densa ou de plantios florestais por multinacionais, quanto tempo isso irá durar, quem administrará os recursos dessa venda, e, finalmente, a duvidosa redução em termos mundiais.

As mudanças climáticas globais são a maior preocupação da humanidade com relação ao aquecimento global. Nesse contexto, os desmatamentos e as queimadas na Amazônia, com reflexos mundiais, constituem exemplos da irresponsabilidade brasileira, onde o argumento de que se outros já o fizeram no passado poder-se-ia repetir o mesmo erro, constitui o maior receio dos países desenvolvidos. No caso da Amazônia, a preocupação refere-se também à destruição da biodiversidade decorrente dos desmatamentos, para, simplesmente, vender a madeira, obter $1,5 \mathrm{mil} \mathrm{kg}$ de arroz ou milho e catorze toneladas de raiz de mandioca e $600 \mathrm{~kg}$ de feijão, no máximo, em duas safras, para serem convertidas em pastagens para durar nos próximos dez anos, transformando em juquira ou em lavouras mecanizadas de grãos, numa contínua "sustentabilidade" parcial.

\section{A biodiversidade do presente e do passado e medidas concretas}

É interessante verificar a facilidade com que a Amazônia tem sido envolvida em mitos e fantasias acerca de suas potencialidades e mistérios. Pode-se afirmar que o primeiro grande mito surgiu com a obsessão da busca da Fonte da Juventude, por Juan Ponce de León (1474-1521), que integrava a segunda viagem de Cristóvão Colombo, em 1493. Juan Ponce de Leon, até a sua morte, em Cuba (1521), descobriu Porto Rico (1506) e a Flórida (13/3/1513), além de ter procurado tenazmente pela Fonte da Juventude. Outro mito a que os exploradores espanhóis se dedicaram foi a busca do El Dorado, nos séculos XVI e XVII, acreditando na existência de fabulosas cidades de ouro e prata, cuja lenda foi transmitida pelos indígenas dos Andes. Sem dúvida, esses mitos foram importantes para a ampliação do conhecimento sobre a geografia, a flora e a fauna da Amazônia, contribuindo assim para realimentar ainda mais os mistérios da região. A primeira descida do rio Amazonas, que recebeu o seu batismo na expedição de Francisco Orellana (1541/ 1542), foi impulsionada pelo mito do El Dorado na crença da busca de riquezas. Há necessidade de dar atenção concreta para a biodiversidade do presente e do passado e retirar a concepção abstrata da biodiversidade do futuro. Da maneira como está sendo colocada, poder-se-á ter uma grande decepção com as expectativas com relação à biodiversidade amazônica. 
No caso da Amazônia, vários produtos extrativos foram destinados ao mercado externo ao longo da história. Entre esses produtos extrativos podem ser mencionados o cacau, a borracha, a castanha-do-pará, o pau-rosa, o babaçu, a madeira, a pesca, entre outros, que chegaram formar ciclos econômicos e que dependem da dotação de recursos naturais. No caso de produtos agrícolas podem ser mencionados a pimenta-do-reino, a soja e o dendê como os principais a serem exportados.

Há determinadas propostas sobre o extrativismo vegetal apoiadas pelos movimentos ambientalistas, governo e pelas próprias entidades de agricultores familiares que apresentam grandes limitações ou escondem outros propósitos políticos. Muitos desses produtos extrativos apresentam conflitos entre a oferta natural e a demanda e correm sérios riscos de perder excelentes oportunidades. Pode-se mencionar algumas delas como exemplos para a geração de renda e emprego:

- A extração do pau-rosa, de que já se chegou a exportar 444 t em 1951 (em 2003 foi de 32t), mostra o potencial que o desenvolvimento dessa cultura representa para a Amazônia, cujo valor poderia ser estimado em dezesseis milhões de dólares sem incluir mais três milhões de dólares do similar sintético importado.

- Os próprios seringueiros do Acre já chegaram à conclusão de que não se pode viver apenas da extração do látex. Basta dizer que a borracha extrativa caiu de quase 23 mil t para pouco mais de 4 mil t (1990-2003) e as importações no período (1992-2003) somam mais de 1,2 bilhão de dólares. O Brasil deve-se precaver de uma possível entrada do mal-das-folhas no Sudeste asiático, como parte das facilidades da globalização, do terrorismo biológico e da busca da auto-suficiência nacional (Davis, 1997).

- Apesar do crescimento do mercado, toda oferta de bacuri é extrativa, indicando que já deveria estar com área plantada semelhante à do cupuaçu, com mais de 25 mil hectares cultivados. Seria possível transformar o Nordeste paraense em um grande centro produtor de bacuri.

- Esse mesmo raciocínio seria válido para o plantio de espécies madeireiras nobres como o mogno, que já deveria estar com plantios em idade de corte de pelos menos 40 mil ha, sem falar em outras espécies madeireiras.

- A exportação de ferro gusa em 2003, de dois milhões de toneladas no Pólo Carajás, indica que é necessário o corte anual de 120 mil hectares de eucaliptos ou de outras espécies madeireiras de rápido crescimento para a produção de carvão vegetal.

- Contínua formação de nichos de mercados como as que se apresentam para cosméticos, fármacos e fruticultura como açaí, taperebá, muruci, pupunha, uxi, pupunha, hortas peri-urbanas etc.

\section{Infra-estrutura de interesse produtivo e social}

Não se pode conceber a inclusão social quando se sabe que no estado do Pará apenas 39\% das propriedades rurais possuem energia elétrica ou somente 
$11 \%$ das estradas federais, estaduais e municipais estão asfaltadas. Nesse contexto, grandes projetos como a CVRD, Petrobras, Alunorte, Eletronorte, Mineração Rio do Norte, Albras, Pará Pigmentos S/A, Jari, entre outros, não podem ficar adotando posturas egoístas, de privilegiar os locais de extração e embarque, mas apresentam responsabilidade por um vasto território, no qual uma parcela dos lucros deveria ser investida em projetos de pesquisa, extensão rural, construção de pontes e estradas etc.

Os investimentos em ciência e tecnologia (C\&T) na Amazônia legal, que representam $3 \%$ do total nacional, deveria quadruplicar, nos próximos dez anos, para acompanhar o percentual da população residente na região. Como o PIB da Amazônia legal foi da ordem de R 82 bilhões de reais em 2001 (6,9\% do País) e o País investiu $0,77 \%$ do PIB em C\&T, isso indica que justificaria aplicar 630 milhões de reais na região. Apesar da dificuldade em quantificar os investimentos em C\&T na Amazônia legal pelo setor público federal e estadual, empresas privadas e de recursos externos, tanto oficiais como clandestinos, deve ser, na melhor das hipóteses, a metade do valor proporcional para a região.

Como na Amazônia legal deve haver uma estimativa de mil a 1,2 mil doutores envolvidos em atividades de pesquisa e ensino, o que representa $3 \%$ do total nacional, há necessidade de se equilibrar com $11 \%$ da população que vive na região. A busca de atividades mais adequadas implica, portanto, a ampliação e a melhoria das atuais instituições de pesquisa e de ensino existentes, mas depende, fundamentalmente, da criação de novas unidades de pesquisa abarcando novas áreas de conhecimento e de abrangência geográfica. A dimensão do espaço amazônico indica que existe um tamanho ótimo e o raio de ação de uma instituição de pesquisa. O estado de Mato Grosso, por exemplo, que concentra 25\% da produção brasileira de soja, $75 \%$ de algodão, sem falar na produção de arroz e milho, do rebanho bovino, não dispõe de unidade de pesquisa agrícola federal. Esta mesma assertiva é válida para os estados do Maranhão e Tocantins, bem como outros campos de conhecimento como a pesca, a floresta, a silvicultura, entre outros.

Em dimensão mundial, países que apresentam grandes contingentes populacionais como a China, a Índia, os Estados Unidos, a Indonésia, o Paquistão, Bangladesh etc. para muitos deles já com limitações de espaço, ou países com alta densidade populacional, que atingem níveis superiores a $400 \mathrm{hab} / \mathrm{km}^{2}$, indica a importância da produção de alimentos e matérias-primas, sobretudo daquelas exigentes em terra, água e luz solar.

\section{Os limites da agricultura familiar na Amazônia}

Com a redução absoluta e relativa da população rural, a agricultura familiar terá de intensificar a sua agricultura. A atual população urbana/ rural na Amazônia indica que cada pessoa no campo precisa produzir alimento para si e para mais duas pessoas que moram nos centros urbanos, sem contar com as exportações. É uma indicação de que é necessário aumentar a produtividade da terra e 
da mão-de-obra e sair da agricultura de derruba/ queima. Com a redução absoluta da população rural, que no Pará atingiu aproximadamente trezentas mil pessoas entre os dois últimos censos demográficos, aumenta o custo de oportunidade da mão-de-obra rural, tornando-se mais lucrativo a sua venda e inviabilizando, também, àquelas atividades com menor produtividade. Diante desse quadro, a perspectiva da elevação dos salários pode levar a um maior assalariamento e subemprego no setor agrícola, inviabilizando atividades intensivas em mão-de-obra da agricultura familiar.

Os estudos de orçamentos familiares realizados no País têm demonstrado que as famílias pobres gastam de 70 a $80 \%$ do que ganham na compra de alimentos. As políticas públicas de apoio à agricultura familiar devem estar direcionadas no sentido de aumentar a produção de alimentos básicos, reduzindo seus preços e, com isso, promovendo um aumento nos salários reais e a distribuição de renda.

As pesquisas sobre agricultura familiar na Amazônia e no Nordeste têm mostrado que a produção comercializada representa $34 \%$ da renda total obtida pela agricultura familiar, o autoconsumo valorizado a preços de mercado representa (19\%), a venda de mão-de-obra $(23 \%)$ e os benefícios das aposentadorias e de serviços públicos comunitários (merendeiras, professoras, agentes de saúde etc.) (17\%) e ajuda decorrente de mutirão e de filhos e parentes que moram fora das comunidades (7\%) (Menezes, 2002). Esses resultados constituem uma indicação de que é necessário efetuar maiores investimentos públicos nas comunidades interioranas, abrindo mais escolas, postos de saúde e, quem sabe, envolvendo as comunidades em programas de recuperação de estradas vicinais, fiscalização ambiental etc. Na medida em que $17 \%$ da renda da agricultura familiar são provenientes de transferências públicas, é importante o papel do governo na geração de novos empregos e na melhoria do bem-estar das comunidades.

Diversos movimentos sociais e ambientais estão criando barreiras para impedir a implantação de grandes projetos de reflorestamento, monocultivos, transgênicos, produtos de exportação ou de criatórios, em favor da agricultura familiar. Isto pode constituir em grande erro estratégico para o País e para atividades que exigem grandes extensões de terra para ganhar economia de escala, como projetos de reflorestamento, agricultura mecanizada, pecuária, entre outros.

Há muitas atividades que são intensivas em mão-de-obra, como a sangria da seringueira, a colheita do cacau, do cupuaçu, do açaí, do coqueiro, do dendê, da pimenta-do-reino, da banana, extração de palmito, da uva etc. Como é bastante difícil inventar uma máquina que vá sangrar a seringueira ou efetuar a colheita dessas culturas, a despeito de existirem máquinas que já realizam a colheita mecanizada do café, da laranja, do tomate, da mandioca, da acerola e da cana-de-açúcar, estas atividades intensivas em mão-de-obra deveria ser mercado cativo da agricultura familiar. Essas culturas, onde seria impossível substituir a mão-de-obra em uma das fases cruciais do processo produtivo, são apropriadas para a agricultura familiar, o que reduziria o contingente de mão-de-obra desempregada. 
A geração de renda e emprego para a massa de excluídos, que engrossam as legiões do MST, dos posseiros em busca de terra e dos desempregados urbanos, constitui o maior desafio das políticas públicas para as próximas décadas. Políticas sociais visando ao fornecimento de alimentos e outras facilidades de inclusão social tornam-se insustentáveis pelo custo, em prejuízo de outros problemas que precisam ser solucionados, além da perda de auto-estima.

\section{Lixo urbano}

Um grande percentual da produção agrícola transforma-se em lixo orgânico sob diversas modalidades, sem falar da parte industrial. É necessário dar novo sentido de limpeza dos núcleos populacionais na Amazônia visando ao seu aproveitamento para a fabricação de compostagem, reduzindo a poluição nos mananciais de água, formação de lixões, etc. e seu aproveitamento na recuperação de áreas degradadas. O rio Amazonas, por exemplo, está se transformando num grande esgoto das cidades ao longo da sua calha (Iquitos, Manaus, Porto Velho, Parintins, Santarém, Macapá etc.).

Os resíduos gerados pelas populações urbanas constitui outra grande preocupação planetária, o que não é diferente no caso da Amazônia. Os resíduos gerados pela natureza são facilmente metabolizados, mas o mesmo não ocorre com os resíduos industriais. Há necessidade de se estabelecer propostas singulares visando ao aproveitamento do componente orgânico do lixo urbano, tais como plásticos, papel, vidros, metais, entre outros. Para muitos desses produtos a decomposição pode levar séculos. $\mathrm{O}$ incremento ao turismo na Amazônia, bastante defendida como opção sustentável, pode acarretar riscos ecológicos, se não for bem administrado. Como as nascentes do rio Amazonas e da maioria de seus afluentes têm suas origens nos Países vizinhos, há necessidade de se estabelecer um condomínio dos países da bacia amazônica.

\section{Ajuda externa para a Amazônia}

A ajuda externa para Amazônia constitui outro tópico que precisa ser avaliado no contexto teórico. As ações ambientais visando à redução dos desmatamentos e queimadas implicam mudanças no processo produtivo, com custos sociais e econômicos, dessa forma, justifica-se, teoricamente, a contrapartida internacional, para a repartição dos prejuízos decorrentes.

Utilizando-se da adaptação do modelo desenvolvido Amelung (1990) com base da teoria do $\operatorname{Coase}^{2}$ (1960), chega-se à conclusão de que a indenização é necessária para atender às propostas ambientais dos países em desenvolvimento $\mathrm{e}$ subdesenvolvidos. A suposição é que existe um custo ambiental reduzido para a região amazônica, representado pela linha $\mathrm{Ca}$ que cresce com a magnitude de desmatamento, na visão local. Os países desenvolvidos teriam uma noção de que os custos ambientais do desmatamento seriam muito maiores (perda da biodiversidade, efeito estufa etc.) representada pela linha Cd (Figura 4). 


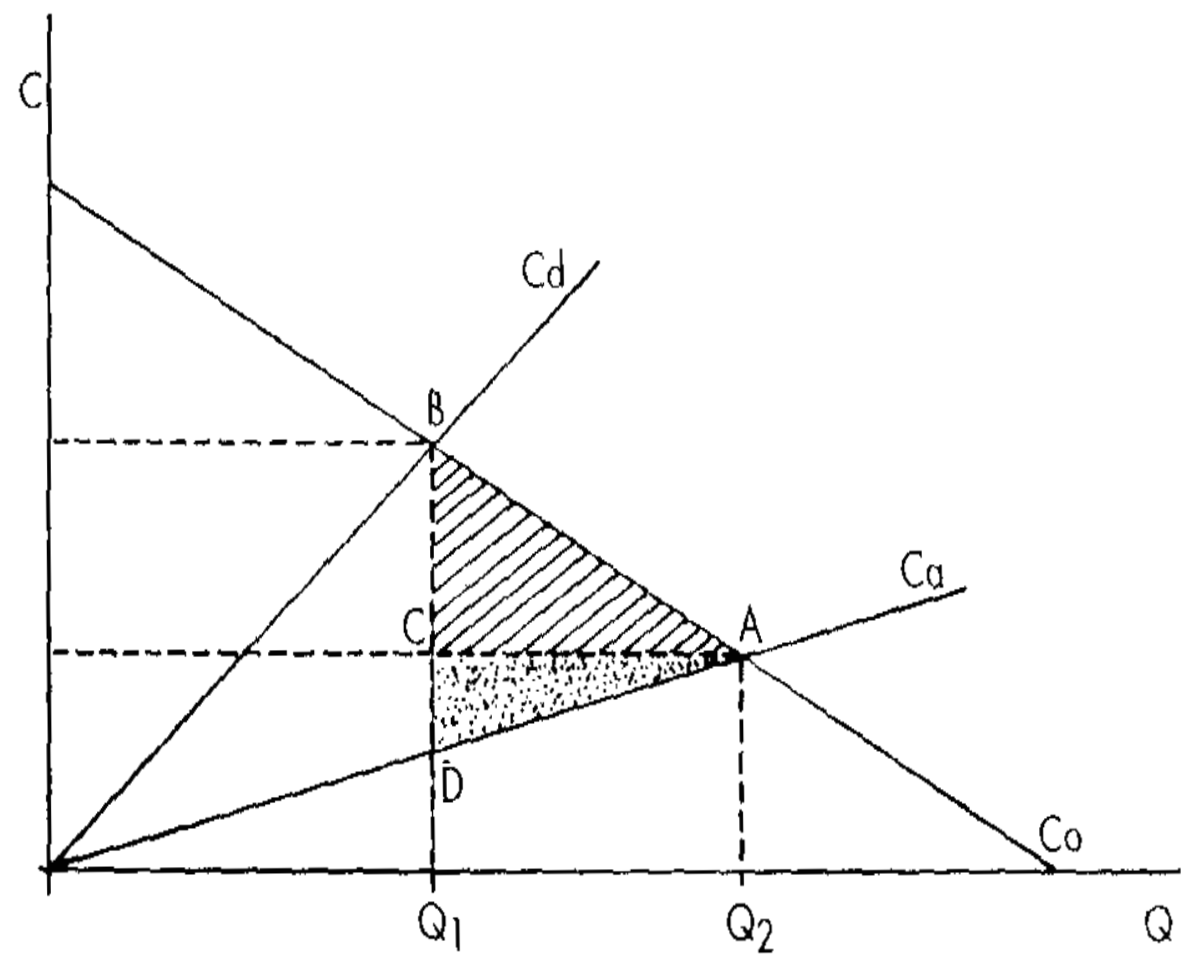

Figura 4 - Compensação econômica pelos países desenvolvidos para reduzir o desmatamento na Amazônia.

À medida que a floresta amazônica for devastada, o seu valor em termos de recursos originais vai decrescer, conforme representação da linha Co (perda de madeira, recursos extrativos, terras degradadas etc.). O cruzamento dessas linhas mostra que os países desenvolvidos desejariam que o desmatamento na Amazônia não ultrapassasse $\mathrm{Q}^{1}$ e os amazônidas pensam em atingir $\mathrm{Q}^{2}$. A redução do desmatamento de $\mathrm{Q}^{2}$ para $\mathrm{Q}^{1}$ implica a redução de benefícios econômicos equivalente ao triângulo $\mathrm{ABD}$. Esse prejuízo econômico deve implicar, portanto, o pagamento pelos países desenvolvidos do valor hipotético representado pelo triângulo $\mathrm{ABC}$, e a região amazônica arcaria com uma parcela representada pelo triângulo ACD, que se justificaria pelo efeito positivo na forma de menores danos ambientais, representado pelo trapézio $\mathrm{Q}^{1} \mathrm{DAQ}^{2}$. A preservação e a conservação da Amazônia exigem, portanto, a necessidade da permanência de atividades econômicas para o conjunto da população regional. Já que os países desenvolvidos estão querendo salvar a Amazônia, a ajuda não constitui um favor, mas uma necessidade multilateral (Amelung, 1990; Homma, 1993).

Uma grande parte dos fundos internacionais para a Amazônia estão sendo destinados para as reservas extrativistas, grupos indígenas, manejo florestal, comunidades, zoneamento agrícola, ciclo do carbono, manejo da várzea, que apresentam grande simpatia externa. Apesar do forte apelo internacional, esses progra- 
mas de ajuda externa refletem muito pouco para a maioria da população, como solução global assumindo ações de natureza unilateral.

Vários programas de pesquisa com financiamento internacional têm provocado, por meio de contrapartidas nacionais em termos de recursos humanos, financeiros e materiais, a realocação dos parcos recursos disponíveis em detrimento das prioridades locais, regionais e nacionais. Em outros casos, a contrapartida estrangeira refere-se a equipamentos e consultorias, dos próprios doadores, promovendo o retorno dos recursos aplicados aos países de origem. Muitos argumentam que os fundos internacionais pagam tudo, mas esquecem de mencionar que ao alocar pesquisadores nacionais, instalações e tempo, estão provocando uma realocação de atividades, interferindo nas prioridades nacionais. Não se quer, com isso, efetuar uma crítica xenofóbica para a ajuda externa, mas estes precisam ser avaliados com mais cautela pelas alocações que provocam na economia, pois possuem efeito multiplicador, geram externalidades e não se descarta até no ângulo inflacionário, se esta ajuda for demasiadamente grande.

A ajuda externa para agricultura (lavoura, pecuária e reflorestamento) para os países subdesenvolvidos e em desenvolvimento, quando estes exportam para os próprios países doadores, terminam refletindo em benefícios para seus consumidores, decorrente da queda dos preços e de produtos de melhor qualidade. $\mathrm{O}$ interesse pela expansão do cultivo da soja nos cerrados esteve relacionado com as políticas do governo japonês decorrente do acordo assinado, em 1974, durante o Governo Geisel, criando o Programa Nipo-Brasileiro de Cooperação para o Desenvolvimento Agrícola da Região do Cerrado (Prodecer). Uma grande parte da produção agrícola dos países subdesenvolvidos e em desenvolvimento destinam-se aos países desenvolvidos. Mencionam uma vasta gama de produtos tropicais e subtropicais como é o caso da soja, cacau, café, dendê, laranja, banana, abacaxi, carne bovina, frangos etc.

No ângulo ambiental, os benefícios seriam mais duvidosos, devido à maioria estar consignado a valor de não-uso e de valor de opção. As propostas ambientais causam, portanto, realocações na economia local, que precisam ser compensadas, daí serem consideradas como via de mão dupla.

\section{Melhorar as relações de trocas comerciais da Amazônia}

A Zona Franca de Manaus, desde a sua criação em 1967, passou da fase comercial que a caracterizou até 1976, passando depois por uma política de substituição de importações que vigorou até 1991 e, a partir daí, para uma nova política industrial. Os benefícios advindos da implantação da Zona Franca de Manaus foram no sentido de transformar Manaus em um pólo industrial, tendo efeito positivo na redução dos desmatamentos nos estados do Amazonas e do Amapá, pela drenagem da população rural, mas provocou o aumento de importações de alimentos e matérias-primas de estados vizinhos provenientes de áreas desmatadas ou importados de locais distantes. 
É preciso entender que uma política de incremento às exportações é sempre uma via de mão dupla. Numa região cuja exportação sempre foi baseada em produtos primários de alto peso/volume, a tendência é que os custos do frete de retorno sejam baixos desestimulando a industrialização local, pelas facilidades de importação. Nesse sentido, é totalmente impossível imaginar que a região seja exportadora exclusiva, onde apenas um sai ganhando. Uma política apropriada seria que todos saíssem ganhando, o que implica o estabelecimento de mecanismos de troca, instalação de beneficiamento conjunto, entre outros. Na região Norte, o saldo da balança comercial foi negativo de 1994 a 2002, somente equilibrando-se em 2003, com pequena magnitude, sem falar nos anos anteriores. No triênio 1995-1997 o déficit da balança comercial superou dois bilhões de dólares anuais, equivalente a um terço do déficit da balança comercial nacional no período, decorrentes das importações da Zona Franca de Manaus, que precisariam ser compensadas com maiores exportações regionais, com mudanças nas relações de troca desfavoráveis e com a verticalização das formas de associação com os países exportadores (Figura 5). O caráter regionalista da geopolítica ama-zônica, que foi desaparecendo com a implantação de grandes programas setoriais (Zona Franca de Manaus, minérios, energia, grãos etc.) tende a destruir ações concretas de propostas de desenvolvimento regional e da atuação conjunta de governos estaduais. Apesar do discurso ambientalista, os países desenvolvidos estão aproveitando a Amazônia como fornecedora de matéria-prima mineral, intensivos em energia e como entreposto comercial de seus produtos industrializados.

As possibilidades de a Amazônia aumentar a sua participação na produção/ exportação de produtos agrícolas vai depender da sua capacidade de responder aos desafios de ordem sanitária (bovinos, produtos agrícolas etc.), de oferta com qualidade, da aplicação dos incentivos econômicos para aqueles que realmente necessitam, da infra-estrutura de exportação, entre outros. No caso da Amazônia, se for associada à tendência mundial de aumento de consumo de produtos que utilizem o mínimo de produtos químicos, produtos verdes e orgânicos, e a valorização da idéia da natureza (prístina) que a região representa, uma significativa fatia do mercado poderia ser abocanhada. Desde que procedimentos corretos sejam adotados com relação ao meio ambiente e à ética social, grande parte dos produtos amazônicos podem ser considerados como orgânicos. Nesse elenco, incluem-se a produção de carne bovina, o reflorestamento, o palmito de pupunha, as frutas nativas, os produtos da floresta, os cosméticos e as plantas medicinais, com grandes possibilidades de serem incluídas na pauta de exportações da Amazônia, desde que sejam feitas com técnicas apropriadas.

É bem provável que o papel da Amazônia no crescimento do mercado de commodities ambientais e de eco-commodities nos próximos anos seja bastante significativo. Mas a pauta de produtos tradicionais, como minérios, energia, produtos eletro-intensivos, carvão vegetal, uso intensivo da água, de terra, de mãode-obra e de produtos poluentes continuarão dominando os rumos da economia regional. É interessante verificar que vários países europeus são reexportadores 
de produtos agrícolas dos países subdesenvolvidos e em desenvolvimento. Os países subdesenvolvidos e em desenvolvimento estão perdendo espaço nos mercados de produtos primários dos quais são grandes produtores, e os países desenvolvidos, a partir dessas mesmas matérias-primas, reelaboram e vendem com marca registrada, capturando a parcela mais substancial da cadeia produtiva, que representa $75 \%$ do preço pago pelo consumidor (Ricupero, 2000).

Não se deve esquecer, também, que o maior mercado brasileiro é o interno, e que não se justifica que produtos que possam ser produzidos no próprio local sejam importados de outros locais distantes ou do exterior (Bacal, 2001). Naturalmente, não se justifica plantar trigo ou batata inglesa na Amazônia ou buscar a auto-suficiência integral, mas também não tem sentido importar maciças quantidades de leite, dendê, cacau, fibra de juta, borracha natural, hortaliças etc. O movimento de globalização deve ser contrastado com um movimento local privilegiando as atividades para o mercado interno, substituição de importações, para o consumo local e sua verticalização.

A melhoria do desempenho das exportações amazônicas vai depender de inovações tecnológicas, do aprimoramento da qualidade e da criação de marcas internacionais e não da desvalorização cambial ou de subsídios artificialmente criados.

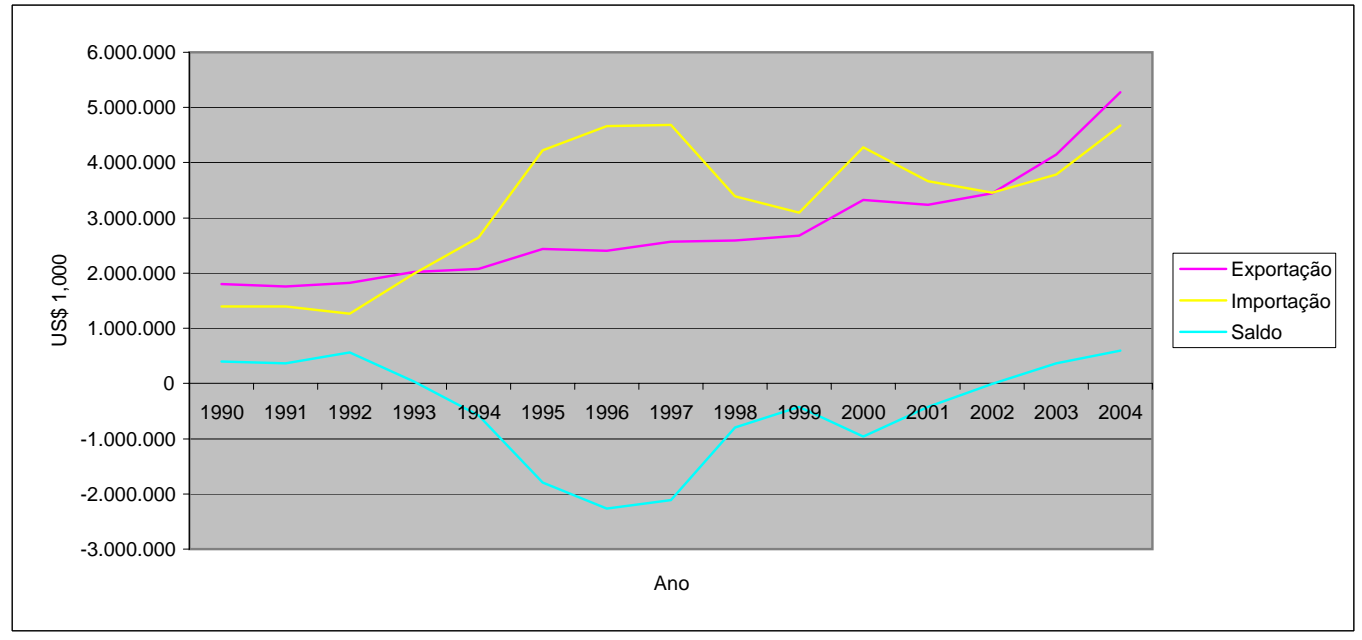

Figura 5 - Balança comercial da Região Norte, 1990-2004 (US\$ 1 milhão).

\section{Conclusões}

A solução dos problemas na Amazônia não são independentes, mas conectada com outras partes do País e do mundo. A redução da extração madeireira predatória na Amazônia, por exemplo, depende dos plantios de madeira no Sul e Sudeste, seus maiores consumidores, bem como da redução da pobreza no Nordeste e dos minifúndios no Sul do País. 


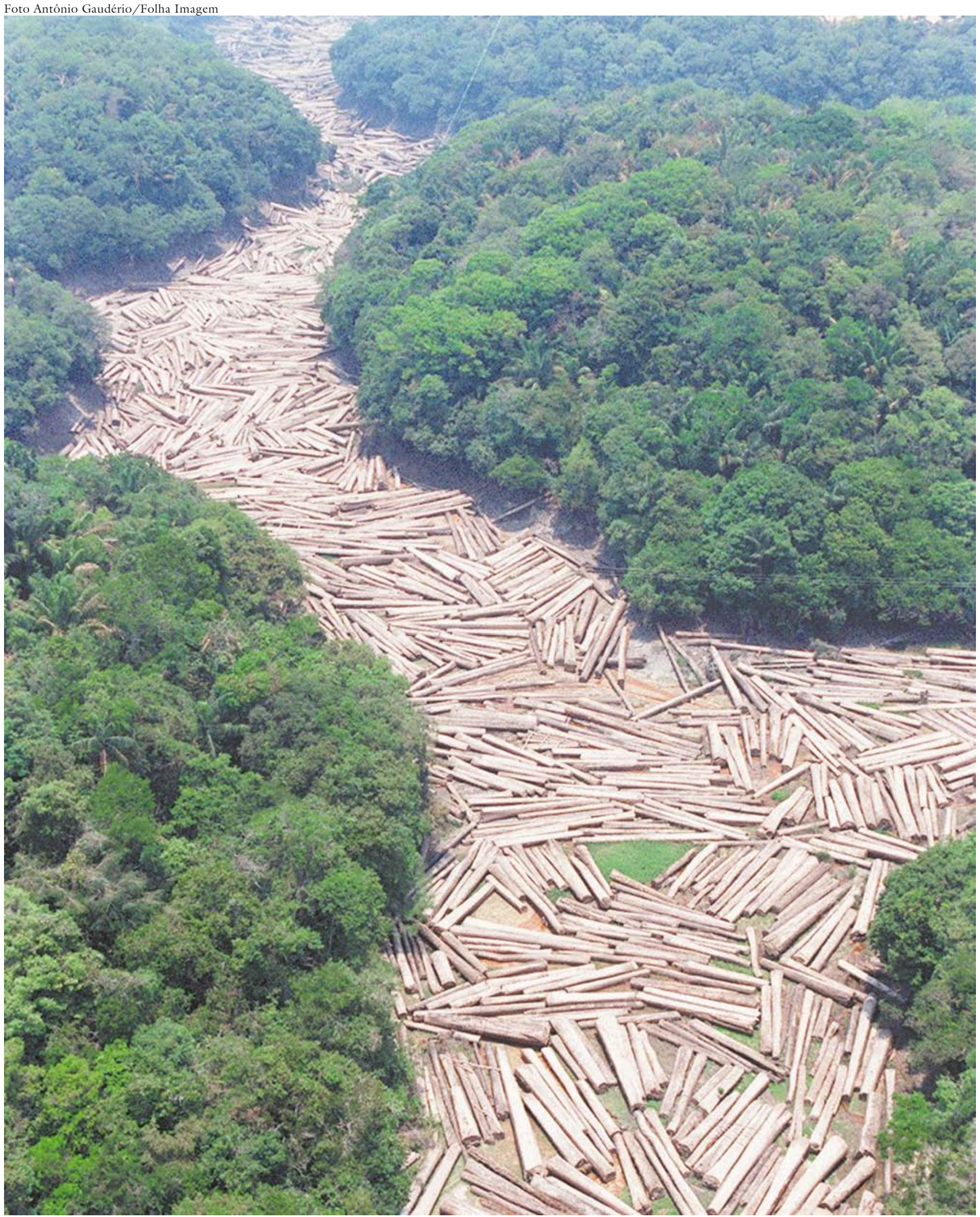

Desmatamento: vista aérea de troncos de árvores cortados ilegalmente na floresta amazônica. 
Em vez de criar barreiras artificiais para tornar mais caras as atividades agrícolas na Amazônia, é mais importante reduzir o custo da recuperação de áreas já desmatadas. A redução dos desmatamentos e queimadas na Amazônia depende do desenvolvimento de atividades agrícolas adequadas nas áreas já desmatadas e que tenham mercado, em vez do uso "sustentável" da floresta e de direitos difusos. Nesse sentido, uma política agrícola teria efeito mais positivo do que uma política ambiental, que não pode ser efetuada de maneira isolada das demais regiões do País, sob risco de transferir contingentes populacionais de outras localidades. Há necessidade de se elevar a produtividade das atividades agrícolas na Amazônia, reduzir a pressão sobre os recursos naturais com risco de esgotamento, incentivar plantios racionais de recursos extrativos potenciais, substituir as importações de produtos tropicais (seringueira, dendê, cacau etc.), melhorar as relações de troca dos produtos amazônicos versus produtos importados da Zona Franca de Manaus, efetuar a recuperação das áreas que não deveriam ter sido desmatadas e utilizar plenamente as áreas já desmatadas, entre outras.

A disponibilidade de recursos, tais como a do FNO, apesar de escassos, não tem sido eficientemente utilizadas, pela reduzida oferta de tecnologia e da fragilidade da extensão rural na Amazônia. O atraso tecnológico do setor agrícola na Amazônia está diretamente relacionado com os impactos na taxa de desmatamento

Os estímulos para melhorar o setor produtivo agrícola são mais importantes para reduzir a pressão do desmatamento, que estão sendo obliteradas pela força política das propostas ambientais, sem, contudo, delinear uma solução econômica concreta para o contingente mais amplo da população regional. Deve-se entender que a geração de empregos no campo é muito mais barata do que nos centros urbanos, que terminam neutralizando as políticas sociais, pelos seus custos astronômicos. Enquanto grandes obras de engenharia na Amazônia têm conseguido transpor obstáculos, a alquimia social ainda debate com soluções banais, como a de deslocar a safra de produtos agrícolas durante a época chuvosa.

Ao longo de sua história, a Amazônia tem sido o receptáculo dos problemas econômicos e sociais de outras regiões do Brasil. Embora seja totalmente impossível repor o estrago efetuado, fazendo voltar atrás e fazer um novo começo, é possível começar uma nova postura com relação à Amazônia e engendrar um novo final.

\section{Notas}

l Gary S. Becker, Prêmio Nobel de Economia 1992.

2 Ronald Coase, Prêmio Nobel de Economia 1991.

\section{Referências}

ALVES, E.; LOPES, M. e CONTINI, E. "O empobrecimento da agricultura brasileira”. Revista de Política Agrícola, Brasília, 8(3), 1999, pp. 5-19. 
ALVIM, P. de T. "Desafio agrícola da região amazônica”. Ciência e Cultura, São Paulo, 24(5), 1972, pp. 437-443.

AMELUNG, T. “Qual política econômica salva al bosque tropical”. Desarrollo y Cooperación, Bonn, n. 3, 1990, pp. 4-6.

BACAL, C. "O paradoxo da exportação". Gazeta Mercantil, São Paulo, 6, 7 e 8 jul. 2001, p. A-3.

BECKER, B. K. Amazônia: geopolitica na virada do III milênio. Rio de Janeiro, Garamond, 2004, 172 p.

BECKER, G. S. “Qual o preço da poluição?” Gazeta Mercantil, São Paulo, 8 nov. 1999, p. A-3.

BRIDGES, W. Mudanças nas relações de trabalho. São Paulo, Makron Books, 1995, 272 p.

COASE, R. "The Problem of Social Cost". The Journal of Law and Economics, 3(1), out. 1960, pp. 1-44.

DALY, H. E. “Crescimento sustentável: uma incongruência”. Desenvolvimento de Base, $15(3), 1991$.

DAVIS, W. “The Rubber Industry’s Biological Nightmare”. Fortune, n. 4, ago. 1997. pp. 86-93.

FREITAS, M. de (org.). A ilusão da sustentabilidade. Manaus, Edições Governo do Estado do Amazonas / Secretaria de Estado de Cultura/ Editora da Universidade do Estado do Amazonas, 2003, 324 p. (Série Amazônia: a terra e o homem).

(org.). Amazônia; a natureza dos problemas e os problemas da natureza. Manaus, Editora da Universidade do Estado do Amazonas, 2001, 60 p. (Coleção Polêmicas da Amazônia, 1).

HOMMA, A. K. O. “Os países desenvolvidos devem pagar pela preservação da Amazônia?” Pará Desenvolvimento, Belém, n. 28, jan.-jun. 1993, pp. 6-9.

História da agricultura na Amazônia: da era pré-colombiana ao terceiro milênio. Brasília, Embrapa Informação Tecnológica, 2003, 274 p.

KINOSHITA, D. L. Uma estratégia para inserção soberana da América Latina na economia globalizada: a questão amazônica. São Paulo, Ifusp, 1999, 4 p. (mimeo.).

MEIRELLES FILHO, J. Amazônia; o que fazer por ela? São Paulo, Editora Nacional, 1986, 86 p. (Coleção Portasabertas, vol. 7).

O livro de ouro da Amazônia; mitos e verdades sobre a região mais cobiçada do Planeta. Rio de Janeiro, Ediouro, 2004, 397 p. (Livro de Ouro).

MENEZES, A. J. E. A. de. Análise econômica da "produção invisível" nos estabelecimentos agricolas familiares no Projeto de Assentamento Agroextrativista Praialta e Piranheira, município de Nova Ipixuna, Pará. Dissertação de Mestrado. Belém, Universidade Federal do Pará, 2002, 130 p.

RICUPERO, R. “Os cafezais de Hamburgo“. A Lavoura, Rio de Janeiro, 102 (631), 2000.

RESUMO - A SOLUÇão dos problemas na Amazônia deve estar conectada com outras partes do País e do mundo. A redução dos desmatamentos e queimadas nessa região depende do desenvolvimento de atividades agrícolas adequadas nas áreas já desmatadas 
e que tenham mercado, em vez do uso "sustentável" da floresta e de direitos difusos. Nesse sentido, uma política agrícola teria efeitos mais positivos do que uma política ambiental que não pode ser efetuada de maneira isolada das demais regiões do País, sob risco de transferir contingentes populacionais de outras localidades. Há necessidade de elevar a produtividade das atividades agrícolas na Amazônia, reduzir a pressão sobre os recursos naturais com risco de esgotamento, incentivar plantios racionais de recursos extrativos potenciais, substituir as importações de produtos tropicais (seringueira, dendê, cacau etc.), melhorar as relações de troca dos produtos amazônicos versus produtos importados da Zona Franca de Manaus, efetuar a recuperação das áreas que não deveriam ter sido desmatadas e plena utilização potencial das áreas já desmatadas, entre outras.

Palavras-chave: Amazônia; subdesenvolvimento sustentado; desglobalização; desmistificação.

Abstract - THE SOlution of the problems in the Amazon is not independent, but connected with other parts of Brazil and the world. The reduction of deforestation and fire in the Amazon depends on the development of appropriate agricultural activities in areas already deforested and that they have market, instead of the "sustainable" use of the forest and of diffuse rights. In that sense, an agricultural policy would have more positive effects than an environmental policy, which cannot be made in an isolated way of the other areas of the country, under the risk of transferring population contingents from other places. There is the need to elevate the productivity of the agricultural activities in the Amazon, to reduce the pressure over the natural resources under exhaustion risk, to motivate rational plantings of potential extractive resources, to substitute the imports of tropical products (rubber, oil palm, cocoa, etc.), to improve the exchange relationship of Amazonian products versus those imported from the Manaus Free Zone, promote the reclamation of areas that should not have been deforested and promote the full potential use of the areas already deforested, among others.

Key-words: Amazon; sustainable underdevelopment; desglobalization; demystification.

Alfredo Homma é agrônomo e concluiu seu doutorado em Economia Rural em 1989, na UFV. Está lotado na Embrapa Amazônia Oriental, onde desenvolve pesquisas sobre extrativismo vegetal, desenvolvimento agrícola e a questão ambiental na Amazônia. Recebeu os Prêmios Nacional de Ecologia (1989), o Prof. Edson Potsch Magalhães (1989), o Frederico de Menezes Veiga (1997), o Jabuti (1999) e o Prof. Samuel Benchimol (2004). Tem cinco livros publicados: Amazônia: meio ambiente e tecnologia agrícola, Extrativismo vegetal na Amazônia: limites e possibilidades, Amazônia: meio ambiente e desenvolvimento agrícola, Cronologia da Ocupação e Destruição dos Castanhais no Sudeste Paraense e História da Agricultura na Amazônia: da era pré-colombiana ao terceiro milênio. @ - homma@cpatu.embrapa.br

Texto recebido em 31/1/2005 e aceito em 18/4/2005. 